\title{
A Case of Clozapine-Associated Pancreatitis
}

\author{
Michele Raja*, ${ }^{, 1}$ and Antonella Azzoni ${ }^{2}$ \\ ${ }^{1}$ Scuola di Specializzazione in Psichiatria, Università degli Studi di Roma "La Sapienza”, Ospedale "S. Andrea”, Rome, \\ Italy; ${ }^{2}$ Servizio Psichiatrico di Diagnosi e Cura, Ospedale "Santo Spirito in Sassia”, Rome, Italy
}

\begin{abstract}
Acute pancreatitis is a very rare complication of clozapine treatment. We report a new case of symptomatic pancreatitis subsequent to starting of clozapine treatment. In this case, the diagnosis of pancreatitis can be considered definitive and the etiological link between clozapine and pancreatitis highly likely. Recovery was not complete. In a 10-year period, we treated 363 cases (196 patients) with clozapine. We diagnosed clozapine-associated pancreatitis only in this patient. However, we did not check amylase and lipase plasma levels in all patients and possibly missed several cases of pancreatitis. We suggest monitoring pancreatic enzymes routinely, at least in the first months of clozapine therapy.
\end{abstract}

Keywords: Antipsychotics, clozapine, pancreatitis, side effects.

\section{INTRODUCTION}

Between 2 and $5 \%$ of cases of acute pancreatitis are drug related [1]. Drugs cause pancreatitis either by a hypersensitivity reaction or by the generation of a toxic metabolite. The autodigestion by proteolytic enzymes activated in pancreas rather than in the intestinal lumen is the suspected pathogenic mechanism. Rechallenge tests, consistent case reports, animal experiments, data on the incidence in drug trials provide evidence of a definite association with pancreatitis for didanosine, valproic acid, aminosalicylates, estrogen, calcium, anticholinesterases, and sodium stibogluconate. An association with pancreatitis is likely, but not definitely proven, for thiazide diuretics, pentamidine, ACE inhibitors, asparaginase, vinca alkaloids, nonsteroidal antiinflammatory drugs, and clozapine [2]. In a pharmacovigilance study of spontaneously reported adverse events [3], 192 patients developed pancreatitis during antipsychotic treatment. Most cases of pancreatitis occurred within 6 months after the start of antipsychotics. Of the reports of pancreatitis associated with antipsychotics, $40 \%, 33 \%, 16 \%$, and $12 \%$ were in patients receiving clozapine, olanzapine, risperidone, and haloperidol, respectively. In $50 \%$ of the patients receiving haloperidol, an atypical antipsychotic was listed as a concomitant drug. Valproate was administered concomitantly in $23 \%$ of patients.

Acute pancreatitis is a very rare complication of clozapine treatment [4]. In the literature, a total of 14 cases of clozapine-induced pancreatitis have been published so far [5]. The pathogenesis of clozapine-associated pancreatitis is unknown. Sani et al. [5] hypothesize that the same mechanism, which has been advanced to explain clozapine agranulocytosis, may fit better to pancreatitis, i.e. clozapineinduced formation of an unstable nitrenium ${ }^{+}$metabolite that in turn induces apoptosis and activation of cytokines and immunoglobulins.

\footnotetext{
*Address correspondence to this author at Via Prisciano 26, 00136 - Rome, Italy; Tel: +39 3473422158; E-mail: michele.raja@libero.it; michele.raja@fastwebnet.it
}

We report a new case of symptomatic pancreatitis subsequent to starting of clozapine treatment.

\section{CASE REPORT}

A 40-year-old man with schizoaffective disorder, bipolar type, was admitted to the Psychiatric Intensive Care Unit (PICU) of a General Hospital for psychotic relapse. He had been treated with haloperidol decanoate $150 \mathrm{mg}$ i.m. every 3 weeks (last dose 20 days before admission). The patient did not present symptoms of any other medical illness. In childhood, he had suffered from pielonephritis and had undergone appendicectomy. He did not drink alcohol. Urine toxic screening (including alcohol) was negative. He was $165 \mathrm{~cm}$ tall and weighed $69.5 \mathrm{~kg}$ (body mass index: $25.5 \mathrm{~kg} / \mathrm{m}^{2}$ ). On admission, routine laboratory (not including amylase and lipase plasma levels) was normal. Blood glucose was 81 $\mathrm{mg} / \mathrm{dL}$ (normal range [NR]: 76-110), serum triglycerides were $109 \mathrm{mg} / \mathrm{dL}$ (NR: 50-200). He presented hallucinations, delusions, mood depression, suicidal ideation, negative symptoms, akinesia, and akathisia. On admission, he asked another patient to be strangulated. Two days after, he cut his wrists with a shuttered mirror. We started clozapine and titrated it up to $100 \mathrm{mg}$ in the morning and $175 \mathrm{mg}$ at bed time on the $18^{\text {th }}$ day of hospitalization. We started lithium, 300 $\mathrm{mg}$ t.i.d., on the $7^{\text {th }}$ day of hospitalization, and added risperidone, $2 \mathrm{mg}$ at bed time, in the first 10 days of clozapine titration. The patient improved. Hallucinations, delusions of guilt and ruin, and suicidal ideation vanished. The intensity of other delusions lessened. Significant side effects were hyper salivation, constipation, and transient tachycardia. Complete Blood Count (CBC) presented a mild granulocytosis. On the $18^{\text {th }}$ day of hospitalization, the patient complained of abdominal pain, without nausea or vomiting. His abdomen was meteoric, tractable, mildly aching. He evacuated abundant, semi-solid, normochromic feces. Body temperature was $36.5^{\circ} \mathrm{C}$. Laboratory analysis showed $25.1\left(10^{\wedge} 3 / \mathrm{uL}\right)$ White Blood Count (WBC), neutrophils 22.2(10^3/uL) (88.7\%), amylase plasma level $1050 \mathrm{U} / \mathrm{L}$ (NR: 5-100), AST $41 \mathrm{U} / \mathrm{L}$ (NR: 2-38), ALT 59 U/L (NR: 2-41), glucose $146 \mathrm{mg} / \mathrm{dL}$ (NR: 76-110), urea $52 \mathrm{mg} / \mathrm{dL}$ (NR: 10-50), creatinine 1.6 
(mg/dL (NR: 0.6-1.20), Ca 14.14 mg/dL (NR: 8.6-10.5), P $6.6 \mathrm{mg} / \mathrm{dL}$ (NR: 2.7-4.5), Na $135 \mathrm{mEq} / \mathrm{L}$ (NR: 136-146), K $4.85 \mathrm{mEq} / \mathrm{L}$ (NR: 3.5-5.1), Cl $95 \mathrm{mEq} / \mathrm{L}$ (NR: 98-110), total bilirubin $1.12 \mathrm{mg} / \mathrm{dL}$ (NR: 0.20-1.19), conjugated bilirubin $0.42 \mathrm{mg} / \mathrm{dL}$ (NR: $0.05-0.3$ ). The results of $\mathrm{CBC}$, triglycerides, amylase and lipase plasma levels are shown in Table 1. Eosinophilia was never present. A plain abdomen film revealed gas distention of right and descending colon and of an ansa of the small intestine in the superior, left quadrant ("sentinel loop"), and gas distention of the gastric bubble. Five hours later, a plain abdomen film revealed airfluid levels in the transverse colon, reduction of the colonic gas distention, and a dilated ansa of the small intestine in the pelvis. An abdominal sonography revealed liver enlargement, normal gallbladder, spleen, and kidneys. Pancreas was not observable for bowel gas. Clozapine and lithium were withdrawn, and oral alimentation was prohibited. Fluid therapy, somatostatine $0.1 \mathrm{mg}$ t.i.d., gabexate $400 \mathrm{mg}$ i.v., omeprazole $100 \mathrm{mg}$ i.v., and ceftriaxone i.v., 1 g. b.i.d were started. In the following 3 days, clinical condition remained stable. Abdomen was tractable, not aching upon palpation. Alveus was open to gas and feces. An abdominal sonography revealed a dilated gallbladder, full of dense bile and biliary sand. Major biliary tract diameter was at upper normal limits $(5 \mathrm{~mm})$. Only a part of pancreas was visible, which showed fine inhomogeneous structure, without focal lesions. Six days after the beginning of pancreatitis, a sonography revealed gallbladder distention (transverse diameter: $5 \mathrm{~cm}$ ), containing mobile, layering sludge echogenic material, wide distension of the main biliary tract $(7 \mathrm{~mm})$, and a mild distension of the left intra-hepatic biliary duct. The pancreas appeared normal, without distension of major ducts. Patient's general condition remained good. He was afebrile. His abdomen was tractable and not aching. Alveus remained open to gas and feces. The patient was referred to a surgical ward where he underwent cholecystectomy, with progressive improving. Ten months after discharge, the patient was admitted again to the PICU for psychotic relapse. He was treated with haloperidol decanoate $100 \mathrm{mg}$ i.m. (last dose 5 days before admission), risperidone $4 \mathrm{mg}$ /day, and valproate $500 \mathrm{mg} /$ day. On admission, pancreatic amylase plasma level was $215 \mathrm{U} / \mathrm{L}(\mathrm{NR}: 15 \div 53)$. Otherwise, laboratory was normal. Temperature was $36.5^{\circ} \mathrm{C}$. He had no pain. His abdomen was tractable. Urine toxic screening (including alcohol) was negative. Valproate plasma level was $26.52 \mu \mathrm{g} / \mathrm{mL}$ (therapeutic range: $50 \div 100$ ). We withdrew valproate and treated him with risperidone $6 \mathrm{mg}$ at bed time, and ox-carbazepine, $1200 \mathrm{mg} /$ day. WBC, triglycerides, amylase and lipase plasma levels are shown in the table. Abdomen sonography was normal, with evidence of past cholecystectomy. Seven days later, the patient was discharged improved with diagnosis of schizoaffective disorder, bipolar type and of chronic pancreatitis.

\section{DISCUSSION}

In this case, the diagnosis of pancreatitis can be considered definitive. We excluded alternative diagnoses (e.g., perforated viscus, acute cholecystitis, intestinal obstruction, etc.). Amylase plasma levels greater than three times normal are indicative of pancreatitis. The temporal relation between pancreatitis and starting of clozapine therapy strongly suggests a causal relationship. The relation between concomitant drugs and pancreatitis seems negligible, although it cannot be excluded definitively. Risperidone had been withdrawn 8 days before onset of pancreatitis. However, WBC rose a few days before amylase levels did and before the diagnosis of pancreatitis was made ( $18^{\text {th }}$ day). This could be the first lab indication of incipient pancreatitis related to risperidone. The association between lithium with pancreatitis is remote. In Medline, there is only one report about possible or probable causal link between lithium and pancreatitis [6] and only one report of alterations in the serum concentrations of calcium, parathyroid hormone, and amylase without features of acute pancreatitis, during an intoxication with lithium [7]. Regarding haloperidol, it had been well tolerated by the patient for years, and its plasma level was decreasing. Furthermore, we excluded alternative common causes of pancreatitis such as gallstones, alcohol abuse, hyper-triglyceridemia, endoscopy retrograde cholangiopancreatography, trauma or previous surgery, by history, echography, plain abdomen film, and laboratory tests. However, the etiological link between clozapine and pancreatitis, although highly likely, cannot be considered definitive because there was no rechallenge to clozapine in patient's follow-up.

Differently from Frankenburg and Kando [8], Chengappa et al. [9] and Garlipp et al. [10], we did not observe eosinophilia, but this abnormality is by no means the rule with clozapine-associated pancreatitis. Differently from the cases reported by Bergemann et al. [11], Garlipp et al. [10], and Sani et al. [5], our patient was symptomatic, as the other eleven cases reported in the literature.

The presence of dense bile and biliary sand is problematic, since the relationship between gallstones and susceptibility to clozapine-associated pancreatitis is unclear. Chengappa et al. [9] reported cholelithiasis in their patient who underwent cholecystectomy. Huang's et al. [12] report of pancreatitis with clozapine several years after cholecystectomy suggests that a lithiasic tendency could predispose to clozapine-induced pancreatitis. Schmitz-Hübsch et al. [13] reported the case of a patient with gallstones who developed recurrent pancreatitis with clozapine. After cholecystectomy, there was no evidence of pancreatitis after clozapine rechallenge. It is not clear whether cholecystectomy aided recovery in our patient since he was already improving before surgery. Unfortunately, recovery was not complete. Although the patient was asymptomatic in the course of his second admission to the PICU, high amylase levels documented chronic pancreatitis.

In a 10-year period, we treated 363 cases (196 patients) with clozapine. We diagnosed pancreatitis in two of them. In one case, we considered pancreatitis induced by alcohol intoxication and/or concomitant valproate treatment. Actually, this patient withdrew valproate and continued clozapine treatment without any further evidence of pancreatitis. Therefore, the incidence of pancreatitis induced by clozapine seems low. However, we did not check amylase and lipase plasma levels in all patients. As Greenberger \& Toskes [1] claim, manifestations of pancreatitis are multiform. If the clinician suspects pancreatitis only in presence of the typical symptoms of the disease, s/he will miss most cases of pancreatitis. Although rare, clozapine associated pancreatitis can have a severe or ominous outcome. We suggest to monitor 
Table 1. The Results of CBC, Triglycerides, Amylase and Lipase Plasma Levels are Shown

\begin{tabular}{|c|c|c|c|c|c|c|}
\hline $\begin{array}{l}\text { First admis- } \\
\text { sion. } \\
\quad \text { Date }\end{array}$ & $\begin{array}{c}\text { WBC } \\
\left(10^{\wedge} 3 / \mathrm{uL}\right)\end{array}$ & Neutrophils (\%) & $\begin{array}{c}\text { Neutrophils } \\
\text { (number) }\end{array}$ & $\begin{array}{l}\text { Amylase (U/L) (labo- } \\
\text { ratory normal range:0- } \\
\qquad 100)\end{array}$ & $\begin{array}{l}\text { Lipase (U/L) (labo- } \\
\text { ratory normal } \\
\text { range: } 5-60)\end{array}$ & $\begin{array}{c}\text { Triglycerides } \\
\text { (mg/dL) (laboratory } \\
\text { normal range: } 50- \\
200)\end{array}$ \\
\hline $2^{\text {nd }}$ day & 6.2 & 60.0 & 3.7 & & & 109 \\
\hline $7^{\text {th }}$ day & 10.0 & 74.0 & 7.4 & & & \\
\hline $12^{\text {th }}$ day & 16.6 & 84.9 & 14.2 & & & \\
\hline $14^{\text {th }}$ day & 14.7 & 80.1 & 11.8 & & & \\
\hline $18^{\text {th }}$ day & 25.1 & 88.7 & 22.2 & 1050 & & \\
\hline $19^{\text {th }}$ day & 14.2 & 74.2 & 10.6 & 675 & 25 & \\
\hline $20^{\text {th }}$ day & 11.0 & 80.2 & 8.9 & 502 & 81 & \\
\hline $21^{\text {st }}$ day & 10.9 & 75.4 & 8.3 & 795 & 250 & \\
\hline $22^{\text {nd }}$ day & 13.8 & 81.2 & 11.3 & 1080 & 431 & \\
\hline $23^{\text {rd }}$ day & 11.0 & 76.2 & 8.4 & 909 & 494 & 126 \\
\hline $24^{\text {th }}$ day & 8.4 & 68.2 & 5.7 & 788 & 234 & \\
\hline $\begin{array}{l}\text { Second admis- } \\
\text { sion. } \\
\text { Date }\end{array}$ & $\begin{array}{c}\text { WBC } \\
\left(10^{\wedge} 3 / \mathrm{uL}\right)\end{array}$ & Neutrophils (\%) & $\begin{array}{l}\text { Neutrophils } \\
\text { (number) }\end{array}$ & $\begin{array}{l}\text { Amylase (U/L) (labo- } \\
\text { ratory normal } \\
\text { range:15-53) }\end{array}$ & $\begin{array}{l}\text { Lipase }(\mathrm{U} / \mathrm{L})(\text { labo- } \\
\text { ratory normal } \\
\text { range: } 0-60)\end{array}$ & $\begin{array}{c}\text { Triglycerides } \\
\text { (mg/dL) (laboratory } \\
\text { normal range: } 50- \\
170)\end{array}$ \\
\hline $2^{\text {nd }}$ day & 5.9 & 59.1 & 3.5 & 215 & 33 & 109 \\
\hline $3^{\text {rd }}$ day & & & & 221 & 26 & \\
\hline $4^{\text {th }}$ day & & & & 213 & 34 & \\
\hline $7^{\text {th }}$ day & & & & 213 & & \\
\hline
\end{tabular}

pancreatic enzymes routinely, at least in the first months of clozapine therapy.

\section{REFERENCES}

[1] Greenberger NJ, Toskes PT. Acute and chronic pancreatitis. In: Fauci AS, Kasper DL, Longo DL, Braunwald E, Hauser LH, Jameson JL, Loscalzo J. Harrison's Principles of Internal Medicine, $17^{\text {th }}$ Ed., Mc Graw Hill, Medical, New York, 2008, pp. 2005-17.

[2] Wilmink T, Frick TW. Drug-induced pancreatitis. Drug Safety 1996; 14: 406-23.

[3] Koller EA, Cross JT, Doraswamy PM, Malozowski SN. Pancreatitis associated with atypical antipsychotics: from the Food and Drug Administration's MedWatch surveillance system and published reports. Pharmacotherapy 2003; 23: 1123-30.

[4] Cerulli TR. Clozapine-associated pancreatitis. Harv Rev Psychiatry 1999; 7: 61-3.

[5] Sani G, Kotzalidis GD, Simonetti A, et al. Development of asymptomatic pancreatitis with paradoxically high serum clozapine levels in a patient with schizophrenia and the CYP1A2*1F/1F genotype. J Clin Psychopharmacol. 2010; 30: 737-9.

[6] Andersen V, Sonne J, Andersen M. Spontaneous reports on druginduced pancreatitis in Denmark from 1968 to 1999. Eur J Clin Pharmacol 2001; 57: 517-21.
[7] Matsis PP, Fisher RA, Tasman-Jones C. Acute lithium toxicity-chorea, hypercalcemia and hyperamylasemia. Aust $\mathrm{N} \mathrm{Z} \mathrm{J} \mathrm{Med}$ 1989; 19: 718-20.

[8] Frankenburg FR, Kando J. Eosinophilia, clozapine, and pancreatitis. Lancet 1992; 340: 251

[9] Chengappa KNR, Pelucio M, Baker RW, Cole D. Recurrent pancreatitis on clozapine re-challenge. J Psychopharmacol 1995; 9: 381-2.

[10] Garlipp P, Rosenthal O, Haltenhof H, Machleidt W. The development of a clinical syndrome of asymptomatic pancreatitis and eosinophilia after treatment with clozapine in schizophrenia: implications for clinical care, recognition and management. J Psychopharmacol 2002; 16: 399-400.

[11] Bergemann N, Ehrig C, Diebold K, et al. Asymptomatic pancreatitis associated with clozapine. Pharmacopsychiatry 1999; 32: 78-80.

[12] Huang YJ, Lane HY, Liao CH, Huang CC. Recurrent pancreatitis without eosinophilia on clozapine rechallenge. Prog Neuropsychopharmacol Biol Psychiatry 2009; 33: 1561-2.

[13] Schmitz-Hübsch T, Schiaepfer TE, Westheide J, et al. Clozapine: acquittal of the usual suspect. World J Biol Psychiatry 2009; 10: $981-4$.

(c) Raja and Azzoni; Licensee Bentham Open.

This is an open access article licensed under the terms of the Creative Commons Attribution Non-Commercial License (http://creativecommons.org/licenses/by-nc/3.0/) which permits unrestricted, non-commercial use, distribution and reproduction in any medium, provided the work is properly cited. 